\title{
Research on uplift model test of single pile in sand
}

\author{
Liuqing Huang ${ }^{1}$, Huibiao $\mathrm{Ma}^{2}$, Qiang $\mathrm{Li}^{2}$, Ling $\mathrm{Hu}^{1}$, Xinyi $\mathrm{Li}^{1}$ \\ ${ }^{1}$ School of Shipping and Maritime, Zhejiang Ocean University, Zhoushan City, Zhejiang Province, China \\ ${ }^{2}$ Ocean Engineering and Equipment College, Zhejiang Ocean University, Zhoushan City, Zhejiang Province, China
}

\begin{abstract}
This paper mainly uses the method of model test to study the ultimate uplift bearing characteristics of a single pile with different length-to-diameter ratios, mainly from the distribution laws of the uplift bearing capacity of the pile, the axial force of the pile and the side friction of the pile perform analysis. The model pile is made of PVC pipe, and resistance strain gauges are attached to both sides of the pipe. The strain value of the PVC pipe under different load conditions is measured to obtain the working behavior of the pile during the process of pulling out the pile. The result shows that the model test data is in good agreement with the numerical simulation.
\end{abstract}

\section{Introduction}

The uplift pile foundation is an important form of foundation for buildings and structures, and is widely used in high-voltage power lines, communication towers and highways.

Regarding the research on uplift piles, a large number of foreign scholars have made relevant experimental and theoretical results. Rao et $\mathrm{al}^{[1]}$ carried out a model experiment of uplift piles in sand. The study showed that as the pile length, the friction coefficient of the pile-soil interface and the sand density increase, the bearing capacity of the pile will also increase accordingly. Dash et $\mathrm{a}^{[3]}$ applied a compressive load to 36 steel pipe model piles, and conducted experiments on the influence of the ultimate pull-out bearing capacity of the model piles. The study showed that the greater the pressure applied, the lower the ultimate pull-out bearing capacity. Krabbenhoftfenxile et $\mathrm{a}^{[4]}$ analyzed the static load experiments of bored cast-in-place uplift piles with two diameters, and discussed the factors affecting the average value of the pile side friction. Luo Yaowu et $\mathrm{al}^{[5]}$ studied the influence of the pile-soil interface on the uplift pile in the sand foundation through the method of model experiment. Research shows that the rougher the pile-soil interface, the greater the lateral pressure coefficient around the pile. Zhou Junpen et a ${ }^{[6]}$ obtained the pile shaft axial force and the pile side friction resistance and the load applied on the pile top through the on-site uplift static load experiment of the mini-single pile. Huang feng et $\mathrm{al}^{[7]}$ used the finite element analysis method to discuss and analyze the pile side friction resistance under the uplift loading mode of the uplift pile, and obtained the theoretical solution of the relationship between the uplift pile load and displacement.
This paper mainly adopts indoor model test method, chooses $1.75 \mathrm{~m}$ and $1.5 \mathrm{~m}$ model piles, analyzing and studying the displacement, pile axial force and pile side friction of a single pile under the uplift load. Obtaining the change law of the axial force of the pile body and the side friction resistance of the pile during the uplifting process. Then, based on the ABAQUS finite element software, the load-displacement curve of the pile and the axial force of the pile body in the model test were verified, and it has good regularity.

\section{Test overview}

\subsection{Experimental setup}

The model box used in the experiment is welded with a $10 \mathrm{~mm}$ steel plate, and the length, width, and height are $2 \mathrm{~m}$, $1 \mathrm{~m}$, and $3 \mathrm{~m}$ respectively. The experimental device is shown in Figure 1.

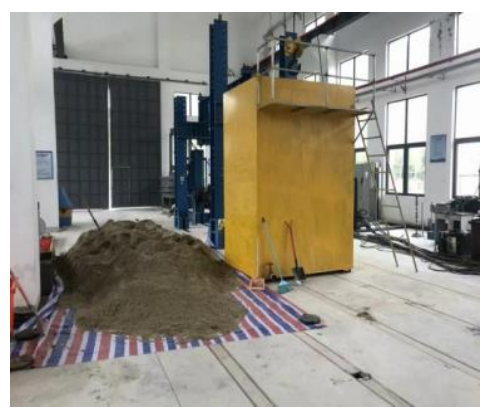

Figure 1. Model box

\subsection{Preparation of model sand}

The sand used in the experiment was collected from the sea sand around Zhoushan. The filling of the model box 
is roughly divided into three parts. The bottom is laid with $0.3 \mathrm{~m}$ thick gravel composed of different particle sizes as the filter layer, and geotextile is laid on the filter layer. Fill the top with fine sand in layers, and compact the soil layer every $25 \mathrm{~cm}$ in thickness.

\subsection{Model pile}

The test pile is made of PVC pipe with a diameter of $32 \mathrm{~mm}$ and an outer wall thickness of $2 \mathrm{~mm}$. A set of 120 ohm resistance strain gauges are symmetrically pasted on one side of the PVC pipe at regular intervals. The outside of the strain gauges were coated with waterproof glue. The wires were drilled into the PVC pipe and sealed with 706 silicone rubber. The exterior is with insulating waterproof tape to prevent seepage. Finally, the bottom of the pipe is sealed with cement mortar grouting.

\subsection{Loading method}

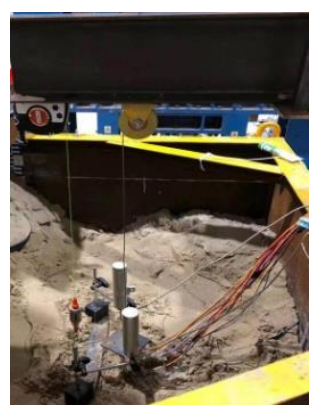

Figure 2. Schematic diagram of anti-pull device

In this test, a vertical uplift load was applied to the model piles through wire ropes, pulley blocks, loading trays and weights, as shown in the figure 2 . The whole test process adopts the slow sustaining load method to load. The displacement of the pile after pulling up is recorded by the observation displacement sensor, and the pulling displacement of the pile is recorded by the observation dial indicator for $5,10,30$, and 60 minutes after the load is applied. After the application, when the pull-up displacement reaches a relatively stable value, the next level of loading is performed.

\section{Model test results and analysis}

\subsection{Analysis of the law of load settlement}

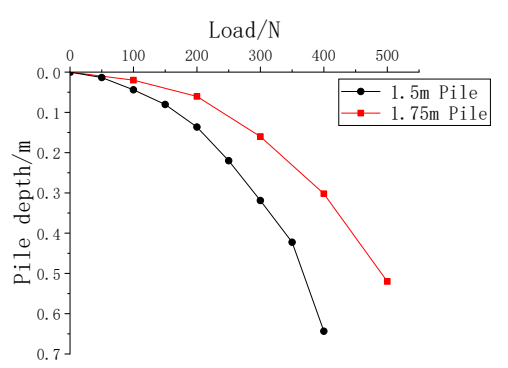

Figure 3. $1.5 \mathrm{~m}$ and $1.75 \mathrm{~m}$ pile load displacement curve
Figure 3 shows the load-displacement curves of different pile lengths in this experiment. It can be seen from the figure that when the load is small, the load-displacement curves of the two piles are relatively smooth. As the load increases, the slope of the curve begins to increase. From the gradual change to the steep change, the lower soil mass changes from elasticity to plasticity. Both the pile and the surrounding soil have a certain amount of displacement, until the pile reaches the ultimate uplift bearing capacity, the displacement of the pile increases rapidly.

\subsection{Analysis of pile shaft axial force}

The $1.75 \mathrm{~m}$ pile is selected as a representative for analysis. According to the pile strain gauges, the pile body's performance during the uplift process is measured. For the strain value, calculate the axial force of the pile body according to the following formula, and obtain the distribution law of the axial force value at each pile section with the pile depth as shown in the figure 4.

$$
\begin{gathered}
\delta_{\mathrm{i}}=\frac{\mathrm{N}_{\mathrm{i}}}{\mathrm{A}}=\mathrm{E} \varepsilon_{\mathrm{i}} \\
N_{i}=E A \varepsilon_{i}
\end{gathered}
$$

Among them: $N_{i}$ is the axial force of the $\mathrm{i}$ section of the pile; $\mathrm{E}$ is the elastic modulus of the pile; $\varepsilon_{i}$ is the average strain of the pile at the section; $\mathrm{A}$ is the crosssectional area of the pile.

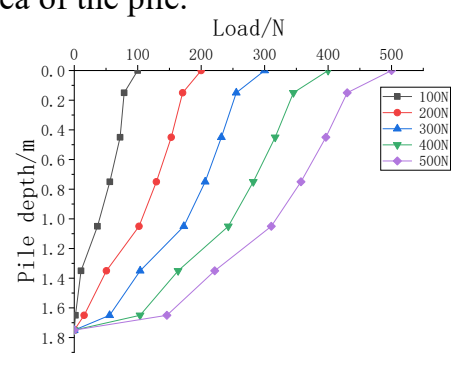

Figure 4. Axial force curve of $1.75 \mathrm{~m}$ pile length

During the whole uplifting process, the axial force of the pile body gradually decreases with the increase of depth. The closer to the top of the pile, the greater the axial force, and the axial force at the end of the pile is zero. The axial force distribution of the uplift pile is not evenly distributed along the length of the pile, but exhibits different deceleration rates. It is mainly manifested in the small change of the axial force on the upper part of the pile and the larger change of the axial force on the lower part. It shows that the axial force of the uplift pile will gradually transfer to the lower part of the pile with the increase of the uplift force, and it will be borne by the soil under the pile.

\subsection{Analysis of pile body friction}

The formula for calculating the side friction resistance of the pile is

$$
q_{s i}=\frac{N_{i+1}-N_{i}}{A_{\text {倾 }}}
$$

Where: $q_{s i}$ is the pile side friction resistance $(\mathrm{KN}) ; N_{i}$ is the axial force of the pile body at point $\mathrm{i} ; P_{i+1}$ is the axial 
force of the pile body at point $\mathrm{i}+1 ; A_{\text {侧 }}$ is the surface area of the pile body from point $\mathrm{i}+1$ to point $\mathrm{i}$.

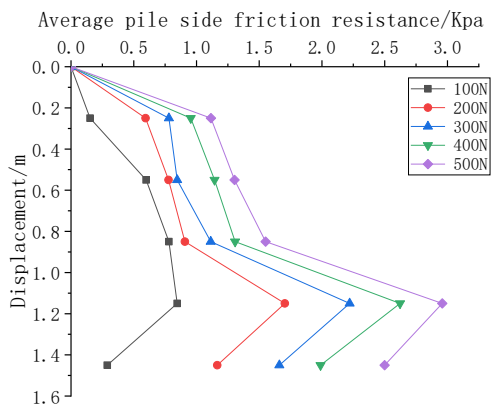

Figure 5. The side friction curve of $1.75 \mathrm{~m}$ pile length

It can be seen from Figure 5 that in different loading stages, the axial force curve of the pile shows different deceleration rates, which reflects the change in the side friction resistance of the pile. Generally speaking, as the uplift load increases, the pile side friction resistance increases first and then decreases. As the load increases, the side friction resistance of the pile changes more and more, until the ultimate pull-out bearing capacity of the pile is reached, and the pile-soil begins to debond. At this time, the pile produces a large displacement until the pile is pulled out.

\section{Numerical simulation analysis of model test}

In this chapter, the ABAQUS finite element analysis software is used to simulate and analyze the pile-soil model of the uplift pile. The ABAQUS finite element software performs very well in solving nonlinear problems, and is especially suitable for research in geotechnical engineering ${ }^{[8]}$.

\subsection{Establishment of calculation model}

This model is mainly composed of two parts: soil and pile. The soil model is selected according to the size of the model test $2 \mathrm{~m}^{*} 1.5 \mathrm{~m}^{*} 3 \mathrm{~m}$, the diameter of the pile is $0.032 \mathrm{~m}$, and the length is $1.5 \mathrm{~m}$. The soil model adopts the Mohr Coulomb model, and the pile adopts the linear elastic model.

\subsection{Analysis of calculation results}

After the model is established, the uplift load is applied to the top surface of the pile according to the step-by-step loading method, and the numerical simulation calculation results are compared with the model test results. As shown in Figure 6, it can be seen from the figure that there are some deviations between the load-displacement curve of the model test and the curve of the numerical simulation, but the two are basically consistent in the elastic stage and has good regularity.

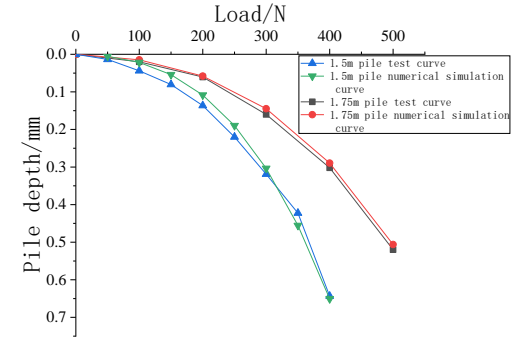

Figure 6. Comparison curve of experiment and numerical simulation

\section{Conclusion}

In this paper, the load-displacement curve of single pile in sand and the lateral friction resistance of the pile shaft are studied by means of model experiments and numerical simulations.

(1) The axial force distribution curve of a single pile mainly decreases with the increase in depth, until it reaches the bottom of the pile, the axial force of the pile is 0 .

(2) The side friction resistance of the pile changes smoothly when the load is small. As the load increases, the slope gradually becomes larger, and the side friction resistance of the pile changes more and more big until it reaches the ultimate uplift bearing capacity of the pile, and the pile soil begins to debond.

\section{Renference}

1. KANAKAPURA S.SUBBA RAO,K.H. VENKATESH. UPLIFT BEHAVIOUR OF SHORT PILES IN UNIFORM SAND[J]. The Japanese Geotechnical Society,1985,25(4).

2. B. K. Dash, P. J. Pise. Effect of Compressive Load on Uplift Capacity of Model Piles[J]. Journal of Geotechnical and Geoenvironmental Engineering,2003,129(11).

3. Sven KrabbenhoftS. Krabbenhoft,Allan AndersenA. Andersen,Lars DamkildeL. Damkilde. The tensile capacity of bored piles in frictional soils[J]. Sven KrabbenhoftS. Krabbenhoft; Allan AndersenA. Andersen;Lars DamkildeL. Damkilde,2008,45(12).

4. Luo Yaowu, Hu Qi, Ling Daosheng, Chen Zheng, Chen Yunmin. Model test study on the influence of pile-soil interface characteristics on the bearing characteristics of uplift piles in sandy soil[J].Rock and Soil Mechanics,2011, 32(03):722-726+732.

5. Zhou Junpeng, Huang Xuefeng, Liu Zilong, Zhu Zhonghua. Research on the mechanical characteristics of the miniature uplift pile foundation[J].Engineering Investigation, 2017, 45(02): 19-24.

6. Huang Feng, Li Guangxin, Zheng Jiqin. Finite element calculation study of pile side friction resistance of single pile under compressive and uplift loads[J]. Engineering Mechanics, 1999(06): $97-$ $101+69$. 
7. Wu Jiangbin, Wang Weidong, Huang Shaoming. Numerical analysis of the uplift bearing characteristics of equal-section piles and expandedbottom piles[J].Rock and Soil Mechanics, 2008(09): 2583-2588.

8. Fei Kang, Zhang Jianwei. The application of ABAQUS in rock mass engineering[M]. Beijing: China Water Power Press, 2010. 